\title{
PVC tracheal tubes exert forces and pressures seven to ten times higher than silicone or armoured tracheal tubes - an in vitro study
}

\author{
[Les tubes trachéaux de PVC exercent des forces et des pressions de sept à dix fois \\ plus élevées que les tubes en silicone ou les tubes armés - une étude in vitro]
}

Hwan S. Joo MD FRCPC, ${ }^{*}$ Mark T. Kataoka MD FRCPC, ${ }^{*}$ Robert J.B. Chen MD FRCPC, ${ }^{*}$ John Doyle MD PhD FRCPC, $\dagger$ C. David Mazer MD FRCPC*

Purpose: Many types of tracheal tubes (TT) including silicone, polyvinylchloride (PVC) and armoured have been used for blind tracheal intubation ( $\mathrm{TI}$ ) via the intubating laryngeal mask airway (ILMA) and may cause trauma to the airway. We examined the maximal in vitro forces and pressures exerted by the tip of various TT as it exits the ILMA.

Methods: Silicone, PVC and armoured TT were studied. A \#5 ILMA was secured on a wooden platform. With the use of a Harvard pump, force was applied to push the TT through the ILMA at $0.34 \mathrm{~cm} \cdot \mathrm{sec}^{-1}$. Forces exerted to push the TT and forces exerted by the TT tips on distal objects were calculated using proximal and distal pressure manometres. The areas of contact between the distal TT tips and the distal objects were measured by planimetry of an imprint. The final pressures exerted by the TT tips on a fixed distal object were calculated by dividing the forces exerted by the areas of contact.

Results: When compared to silicone and armoured TT, PVC TT exerted seven to ten times higher forces and pressures on distal objects. $(P<0.05)$. Heating PVC TT and inserting PVC TT with reverse curvature to the ILMA did not decrease the forces and pressures exerted by the distal tip.

Conclusion: The high forces and pressures exerted by PVC $\Pi T$ may theoretically contribute to increased morbidity to patients' airway and esophagus. Caution should be exercised before attempting blind TI via the ILMA with a PVC TT.
Objectif : De nombreux types de tubes trachéaux (TT), dont les tubes de silicone, de polychlorure de vinyle (PVC) et les tubes armés, ont été utilisés pour l'intubation trachéale (IT) à l'aveugle au travers du masque laryngé d'intubation (MLI), mais ils peuvent causer des traumatismes aux voies aériennes. Nous avons vérifié les forces et les pressions maximales in vitro exercées par la pointe de divers TT au moment où ils sortent du MLI.

Méthode : Des TT de silicone, de PVC et armés ont été étudiés. Un MLI no 5 a été fixé à une plate-forme de bois. À l'aide d'une pompe Harvard, une force à été appliquée pour pousser le TT dans le MLI à $0,34 \mathrm{~cm} \cdot \mathrm{sec}^{-1}$. Les forces exercées pour pousser le $T T$ et celles des pointes de TT sur des objets distaux ont été calculées en utilisant des manomètres de pression proximale et distale. Les surfaces de contact entre les pointes de TT distales et les objets distaux ont été mesurées par planimétrie d'une empreinte. Les pressions finales exercées par les pointes de TT sur un objet distal fixe ont été obtenues en divisant les forces exercées par les surfaces de contact.

Résultats : Comparés aux TT de silicones et aux TT armés, les TT en PVC exercent des forces et des pressions de sept à dix fois supérieures sur des objets distaux $(P<0,05)$. Le réchauffement des TT en PVC et leur insertion selon une courbure renversée par rapport à celle du MLI ne diminuent pas les forces et les pressions exercées par la pointe distale.

Conclusion : Les importantes forces et pressions exercées par les TT de PVC contribuent, théoriquement, à l'accroissement de la morbidité des voies aériennes et de l'œsophage. II faut procéder avec prudence à l'IT à l'aveugle par le MLI avec un TT en PVC.

From the Departments of Anaesthesia, St. Michael's Hospital ${ }^{*}$ and the University Health Network, $†$ University of Toronto, Toronto, Ontario, Canada.

Address correspondence to: Dr. Hwan Joo, Department of Anaesthesia, St. Michael's Hospital, University of Toronto, 30 Bond Street Toronto, Ontario M5B 1W8, Canada. Phone: 416-864-5071; Fax: 416-864-6014. E-mail: hwanjoomd@yahoo.com

Reprints will not be available from the author. Vitaid ${ }^{\mathrm{TM}}$ Toronto, Canada provided silicone and armoured tracheal tubes for this study. No other financial support was received for this study.

Accepted for publication April 18, 2002.

Revision accepted July 22, 2002. 
A dedicated tracheal tube (TT) made of soft silicone (Vitaid ${ }^{\mathrm{TM}}$ Toronto, Canada) has been specifically developed for use with the intubating laryngeal mask airway (ILMA). ${ }^{1}$ Due to the high cost of this silicone TT, TT made of polyvinylchloride (PVC) and armoured tubes have been used with the ILMA. ${ }^{2-9}$ The non-silicone tubes also have the advantage of being single use and easily accessible.

Blind tracheal intubation (TI) attempts can result in esophageal intubation and/or airway trauma. ${ }^{10,11}$ Although rare, major complications can occur. TT with tips that exert higher forces and pressures may be at higher risk for causing esophageal and/or airway damage during blind TI attempts via the ILMA. This study was performed to measure, in vitro, the maximal forces and pressures that can be exerted by the tip of the TT before the distal end of the TT, which exits the ILMA, buckles. The maximal force/pressure before buckling was used in this study, as there is a rapid decrease in force/pressure after the TT buckles.

\section{Material and methods}

Three types of TT were studied: silicone, PVC, (Mallinckrodt Hi-Lo, Hazelwood, MO, USA), and armoured (Phycon, Bunkyo-ku, Tokyo). The Phycon armoured TT was tested because, unlike other armoured TT, it has a removable connector. PVC TT were also tested when introduced with reverse curvature to the ILMA, ${ }^{4}$ and after warming in $43^{\circ} \mathrm{C}$ water for one minute. For all TT, $7.5 \mathrm{~mm}$ internal diameter (ID) TT were studied. However, for silicone and nor- mal curvature PVC TT, $7.0 \mathrm{~mm}$ and $8.0 \mathrm{~mm}$ TT were also studied. Forces were measured with the tip of the TT situated at $5 \mathrm{~cm}$ from the opening of the ILMA since, when esophageal intubation occurs, resistance to TT advancement will occur at $5 \mathrm{~cm}$ past the distal opening of the ILMA. ${ }^{12}$ The test was repeated with five lubricated TT for each group.

A \#5 ILMA was secured on a wooden platform attached to a Harvard apparatus pump (Holliston, MA, USA; Figure 1). The Harvard pump applied the force necessary to advance the TT through the ILMA at $0.34 \mathrm{~cm} \cdot \mathrm{sec}^{-1}$. Maximal forces at the proximal and distal tip of the TT before the distal end of the TT buckled were measured using two pressure transducers (DNI Nevada, Carson City, NV, USA) attached to a $10-\mathrm{mL}$ saline filled glass syringe in series with the TT. Pushing force (the force exerted on the proximal end of the TT) was calculated from the pressure in the proximal syringe multiplied by the cross sectional area of the syringe barrel $\left(154 \mathrm{~mm}^{2}\right)$. Transmitted force (the force exerted by the distal tip of the TT) was calculated from the pressure in the distal syringe. The pressure exerted by the tip of the TT was calculated from the transmitted force divided by the area of contact of the distal TT tip before the distal end of the TT buckled. The area of contact was measured by planimetry of an inked imprint using Sigmascan ${ }^{\mathrm{TM}}$, (Chicago, IL, USA). Data was analyzed using Sigmastat ${ }^{\mathrm{TM}}$ statistical software (Chicago, IL, USA). Linear regression was performed to determine the strength of correlation between TT size and force/pressure exerted on distal objects. One-way

TABLE Forces and pressures exerted by the tracheal tube $5 \mathrm{~cm}$ past the ILMA opening

\begin{tabular}{|c|c|c|c|c|c|}
\hline & $\begin{array}{l}\text { Silicone } 7.5 \\
\mathrm{~mm}\end{array}$ & $\begin{array}{l}\text { Armoured } 7.5 \\
\mathrm{~mm}\end{array}$ & PVC $7.5 \mathrm{~mm}$ & $\begin{array}{l}\text { PVC } 7.5 \mathrm{~mm} \\
\text { inserted } \\
\text { backwards }\end{array}$ & $\begin{array}{l}\text { PVC } 7.5 \mathrm{~mm} \\
\text { heated } \\
\text { to } 43^{\circ} \mathrm{C}\end{array}$ \\
\hline $\begin{array}{l}\text { Proximal pushing force } \\
\text { for passage through ILMA } \\
\text { (Newtons) }\end{array}$ & $2.22 \pm 0.74^{*}$ & $2.22 \pm 0.10^{*}$ & $5.38 \pm 1.31$ & $6.78 \pm 1.58$ & $6.36 \pm 1.54$ \\
\hline $\begin{array}{l}\text { Maximal proximal pushing } \\
\text { force before distal tip of } \\
\text { tracheal tube buckles (Newtons) }\end{array}$ & $8.58 \pm 3.33^{*}$ & $8.01 \pm 1.31 *$ & $42.34 \pm 23.02$ & $32.03 \pm 5.65$ & $40.37 \pm 9.57$ \\
\hline $\begin{array}{l}\text { Maximal distal transmitted } \\
\text { force before distal tip of } \\
\text { tracheal tube buckles } \\
\text { (Newtons) }\end{array}$ & $6.78 \pm 1.56^{*}$ & $4.76 \pm 0.33^{*}$ & $13.10 \pm 0.88$ & $13.30 \pm 5.19$ & $8.99 \pm 1.25$ \\
\hline $\begin{array}{l}\text { Area of distal tracheal tube } \\
\text { tip contact at maximal } \\
\text { distal transmitted pressure }\left(\mathrm{mm}^{2}\right)\end{array}$ & $107 \pm 12 \dagger$ & $67 \pm 9.8 \dagger$ & $32 \pm 2.5$ & $24 \pm 6.0$ & $28 \pm 5.3$ \\
\hline $\begin{array}{l}\text { Maximal pressure exerted by } \\
\text { tip of tracheal tube }(\mathrm{mmHg})\end{array}$ & $551 \pm 141^{*}$ & $629 \pm 141^{*}$ & $3530 \pm 242$ & $5005 \pm 2463$ & $2935 \pm 891$ \\
\hline
\end{tabular}

ILMA = intubating laryngeal mask airway; PVC = polyvinylchloride. All numbers expressed as mean \pm standard deviation.

* Significantly less than the PVC groups, $P<0.05$. †Significantly different compared to all other groups, $P<0.05$. 


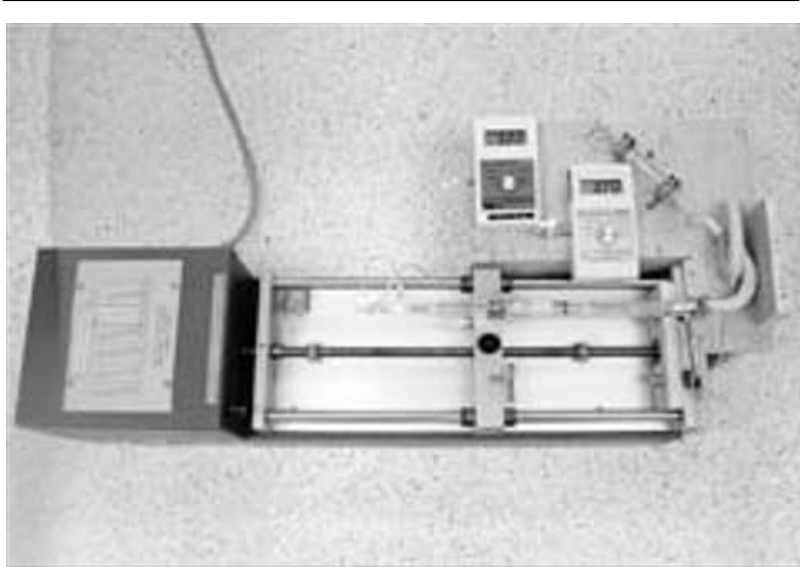

FIGURE 1 Apparatus for measurement of proximal tracheal tube pushing forces and distal forces transmitted by the tracheal tube on a fixed object.

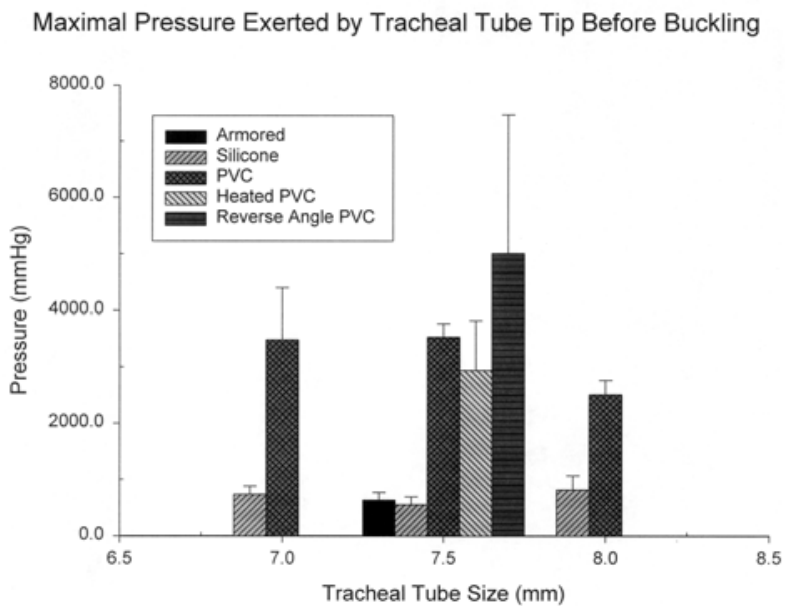

FIGURE 2 Maximal pressure exerted by tracheal tube tip before buckling. All numbers expressed as mean \pm standard deviation. PVC $=$ polyvinylchloride. ${ }^{*}$ All PVC tracheal tubes $(\mathrm{TT})$ exerted higher pressures when compared to silicone and armoured TT $(P<0.05)$.

ANOVA with Tukey test for all pair wise comparison was used for comparison between groups. A P value of $<0.05$ was considered significant.

\section{Results}

The results for $7.5 \mathrm{~mm}$ TT are shown in the Table. PVC TT required higher initial force to overcome the friction from passage through the ILMA. Once the
TT contacted the fixed object $5 \mathrm{~cm}$ from the opening of the ILMA, the distal end of the PVC TT did not buckle until pushing forces approximately eight times higher than those required for silicone TT, were used. These forces were transmitted to the distal object with the PVC TT. Both silicone and armoured TT required lower initial force to overcome friction associated with passage through the ILMA. Less force was also transmitted to distal objects before the distal end of the TT buckled. The silicone TT exerted half the force exerted by the PVC TT. The areas of distal tip contact at maximal distal transmitted forces were also significantly larger in the silicone and armoured TT when compared to PVC TT. This lead to better distribution of force on distal objects, resulting in lower pressures. The actual maximal pressure exerted was almost seven times higher in the PVC group when compared to the silicone group. Heating and introduction with reverse curvature of PVC TT did not decrease the pressure exerted by the TT on distal objects (Figure 2). There was poor correlation between the size of the TT and the forces and pressures exerted on distal objects. The $\mathrm{r}^{2}$ value was 0.33 for PVC and 0.03 for silicone TT.

\section{Discussion}

The ILMA has been advocated for use for TI in patients with difficult airways. ${ }^{6,13,14}$ Difficult TI has been associated with damage to the larynx and the esophagus. ${ }^{15,16}$ When performing blind TI attempts with the ILMA, malplacement of the TT is not uncommon. After multiple TI attempts with a silicone TT, fatal esophageal perforation in an elderly female with an esophageal pouch was reported. This is a rare event. However, with the current use of stiffer TT, the possibility of airway and/or esophageal morbidity may be of concern. Potential injuries include arytenoid dislocation, vocal cord tear and perforation of pyriform sinus.

The results of this study show that different types of TT can exert vastly different forces and pressures on distal structures when used with the ILMA. Also, the design of the tip of the TT can be a major factor in the amount of pressure that is applied to distal structures. The silicone TT had the most favourable characteristics. The silicone TT has a soft tip which deforms easily so that force is widely distributed, leading to lower maximal pressures exerted. Theoretically, the extremely high forces and pressures exerted by PVC TT may contribute to increased morbidity. Whether this model transfers to actual human clinical care is unknown.

It was beyond the scope of this study to examine every type of TT available on the market. It was also beyond the scope of this study to directly compare the efficacy of different TT types/designs when used with 
the ILMA. However, overall success rates for blind TI with PVC and silicone TT are similar: $94-97 \%$ vs $96 \%$ respectively. ${ }^{6,7,13,17}$ The decision to use a specific type of TT with the ILMA will ultimately rest on the clinician, based on experience, perceived efficacy, perceived safety profile, cost and availability. However, until further studies are performed on the safety and efficacy of various TT on human subjects, clinicians should be cautious when attempting blind TI with PVC TT via the ILMA and excessive force must not be used. If PVC TT are used, fibreoptic guidance may be beneficial not only in improving success rates ${ }^{6}$ but also in avoiding unnecessary trauma associated with blind TI via the ILMA.

\section{Acknowledgement}

The authors would like to thank Mr. Garfield Hall for his technical and engineering support.

\section{References}

1 Brain AI, Verghese C, Addy EV, Kapila A. The intubating laryngeal mask. I: development of a new device for intubation of the trachea. Br J Anaesth 1997; 79: 699-703.

2 Asai T. Mallinckrodt reinforced tube for tracheal intubation through the intubating laryngeal mask. Can J Anaesth 1998; 45: 1221-2.

3 Asai T, Matsumoto H, Shingu K. Awake tracheal intubation through the intubating laryngeal mask. Can J Anesth 1999; 46: 182-4.

4 Joo $H$, Rose $K$. Fastrach-a new intubating laryngeal mask airway: successful use in patients with difficult airways. Can J Anaesth 1998; 45: 253-6.

5 Joo HS, Rose DK. The intubating laryngeal mask airway with and without fiberoptic guidance. Anesth Analg 1999; 88: 662-6.

6 Joo HS, Kapoor S, Rose DK, Naik VN. The intubating laryngeal mask airway after induction of general anesthesia versus awake fiberoptic intubation in patients with difficult airways. Anesth Analg 2001; 92: 1342-6.

7 Lu PP, rang CH, Ho AC, Shyr $M H$. The intubating LMA: a comparison of insertion techniques with conventional tracheal tubes. Can J Anesth 2000; 47: 849-53.

8 Lu PP, Brimacombe J, Ho AC, Shyr MH, Liu HP. The intubating laryngeal mask airway in severe ankylosing spondylitis. Can J Anesth 2001; 48: 1015-9.

9 van Vlymen JM, Coloma M, Tongier WK, White PF. Use of the intubating laryngeal mask airway: are muscle relaxants necessary? Anesthesiology 2000; 93: 340-5.

10 Domino KB, Posner KL, Caplan RA, Cheney FW. Airway injury during anesthesia: a closed claims analy- sis. Anesthesiology 1999; 91: 1703-11.

11 Branthwaite MA. An unexpected complication of the intubating laryngeal mask. Anaesthesia 1999; 54: 166-7.

12 Brimacombe J, Brain A, Berry AM. Intubating Laryngeal Mask, the Laryngeal Mask Airway - A Review and Practical Guide. W.B. Saunders, 1997: 230-41.

13 Ferson DZ, Rosenblatt WH, Johansen MJ, Osborn I, Ovassapian A. Use of the intubating LMA-Fastrach in 254 patients with difficult-to-manage airways. Anesthesiology 2001; 95: 1175-81.

14 Langeron O, Semjen F, Bourgain JL, Marsac A, Cros $A M$. Comparison of the intubating laryngeal mask airway with the fiberoptic intubation in anticipated difficult airway management. Anesthesiology 2001; 94: 968-72.

15 Rieger A, Hass I, Gross M, Gramm HJ, Eyrich K. Intubation trauma of the larynx-a literature review with special reference to arytenoid cartilage dislocation (German). Anasthesiol Intensivmed Notfallmed Schmerzther 1996; 31: 281-7.

16 Benumof JL. Management of the difficult adult airway. With special emphasis on awake tracheal intubation. Anesthesiology 1991; 75: 1087-110.

17 Baskett PJ, Parr MJ, Nolan JP. The intubating laryngeal mask. Results of a multicentre trial with experience of 500 cases. Anaesthesia 1998; 53: 1174-9. 